\title{
REMUNERAÇÃO E COMPETENNCIAS: RETÓRICA OU REALIDADE?
}

\section{RESUMO}

Este artigo objetiva refletir sobre a articulação entre práticas de remuneração e a noção de competências mediante a análise de um modelo organizacional. A crescente utilização da noção de competências como referência para a gestão de pessoas desperta o interesse na forma como se aplica ao processo de remuneração em face das limitações do sistema tradicional de remuneração num contexto de constantes mudanças. Por meio de pesquisa qualitativo-descritiva, tendo como principal instrumento para a coleta de dados a entrevista semi-estruturada, verificou-se que a vinculação entre remuneração e competências ocorre por meio processo de avaliação de desempenho, e que se fazem presentes várias contradições entre a concepção do modelo e sua aplicação, instigando uma discussão sobre a retórica e a realidade desse tipo de prática. Além disso, percebe-se a complexidade e a diversidade de variáveis envolvidas na arquitetura de um modelo de remuneração e sua operacionalização.

\section{Júnia Marçal Rodrigues}

UFMG

ABSTRACT This study is a reflection on compensation and competences articulation analyzing an organizational model. The increased use of competencies' notion as reference for human resources management raises the interest in how it is applied to compensation processes considering the limitations of the traditional model of remuneration in a context of constant changes. A qualitative-descriptive research was carried on based upon semi-structured interviews as the basic method for data collection. The results indicate that compensation and competencies articulation occurs through performance evaluation and there are many contradictions between the conception of the model and its application paving the way for a discussion about the rhetoric and the reality of this practice. It also indicates the complexity and diversity of the variables involved in building a compensation model and its management.

PALAVRAS-CHAVE Remuneração, competências, desempenho, gestão de pessoas, organizações.

KEYWORDS Compensation, competences, perfor mance, people management, organizations. 


\section{INTRODUÇÃO}

Entre as razões que são apresentadas pelos estudiosos do sistema de remuneração baseado em competências para que as empresas que buscam a vantagem competitiva adotem essa forma de compensação, destacam-se principalmente a inovação tecnológica e o aumento da competição global.

Embora esteja crescendo o apelo à utilização de competências vinculadas às estruturas de remuneração, ainda não se estabeleceu solidamente a maneira como isso deve acontecer. A literatura sobre o tema não apresenta um consenso quanto ao tipo de remuneração ao qual o conceito de competências deveria estar vinculado, se à remuneração fixa ou à remuneração variável (Hipólito, 2000; Lawler III, 1986; Ribeiro, Guimarães e Souza, 2001; Wood Jr., 1997). E em relação à realidade brasileira, em resultados de pesquisa, verifica-se que entre as empresas que possuem modelo de gestão baseado em competências são poucas as que articulam o conceito de competências à remuneração (Barbosa, 2001).

0 estudo específico da articulação entre remuneração e competências demanda a compreensão de diferentes elementos da dinâmica organizacional que se influenciam mutuamente viabilizando a recompensa da contribuição das pessoas em função de suas competências. Para tanto, deve-se considerar a perspectiva estratégica da organização e suas competências, que são desdobradas em competências individuais necessárias ao alcance dos resultados esperados. A gestão de pessoas assume papel preponderante nesse processo, pois viabiliza a gestão de competências desde sua identificação, desenvolvimento, avaliação e posterior recompensa.

Portanto, refletir sobre a retórica e a realidade da remuneração baseada em competências consiste em conhecer em profundidade a dinâmica de tal modelo por meio de uma análise pormenorizada com base em múltiplos olhares. Para o al cance desse objetivo, a pesquisa foi realizada com um estudo de caso por meio de entrevistas semi-estruturadas, análise de documentos e observação. Os dados obtidos foram analisados de forma descritiva e qualitativa, permitindo a contraposição dos diferentes atores envolvidos com o modelo de remuneração e competências, sinalizando assimetrias entre aquilo que a organização formalmente preconiza sobre o modelo e sua operacionalização nas diferentes unidades que foram pesquisadas.

A abordagem teórica está subdividida em três partes principais que abordam conceitos e princípios necessá- rios à compreensão da vinculação entre a remuneração e a noção de competências. A presenta uma discussão sobre remuneração que vai do enfoque tradicional, baseado no cargo e vinculado à estrutura organizacional, ao enfoque estratégico, que propõe o reconhecimento dos resultados individuais, junto aos resultados organizacionais, como base para a remuneração. Isso prepara a discussão realizada na seqüência, quando são abordadas a contextualização da noção de competências e sua inserção no âmbito da gestão de pessoas. Numa discussão sobre a definição desse termo, verifica-se a complexidade teórica que circunda tal questão, refletindo-se, inclusive, na aplicação da noção de competências em modelos organizacionais. Por fim, a vinculação da noção de competências às práticas de remuneração articula a noção do desempenho e sua avaliação como mecanismo principal para recompensa das competências.

\section{BREVE REFLEXÃO TEÓRICA}

\section{Sobre remuneração}

A gestão da remuneração nas organizações se traduz na operacionalização de programas e estruturas de pagamento que podem ser identificadas com base em dois eixos: o modelo tradicional, que tem como referência o cargo para a consolidação dos planos de cargos e salários, e a abordagem estratégica, que tem como principio central o reconhecimento da contribuição das pessoas como fator a ser remunerado, principal mente por meio dos programas de remuneração variável.

Para Lawler III $(1986,1990)$, a abordagem tradicional de remuneração reflete, em última instância, uma forma de pensar o trabalho ea relação com as pessoas que se encaixa bem num sistema de gestão burocrático, fortemente hierarquizado e voltado para o controle rígido. Vale ressaltar a forte correl ação, estabel ecida pela administração científica, entre a forma de se organizar o trabalho e as políticas de remuneração, quando Taylor estabelece o vaIor dos salários com base na acentuada divisão de tarefas (Brisolla, 1994).

A lógica para a definição do valor do salário - nesse modelo tradicional - se baseia na mensuração do valor relativo do cargo e do valor pago pelo mercado. Para isso é real izada uma sobreposição entre a estrutura de cargos e os val ores dos salários. A estrutura de cargos é el aborada com base nas descrições de cargo (documento que registra objetivos, tarefas, responsabilidades e requisitos de um cargo), que são avaliadas visan do a definir uma hierarquia entre eles. A estrutura de salários é definida com base em 


\section{JÚNIA MARÇAL RODRIGUES}

pesquisas de mercado, quando se conhece a freqüência e amplitude dos salários pagos aos cargos em análise.

No entanto, o formato e o conteúdo dos cargos se al teraram significativamente em função das transformações estruturais, tecnológicas, de processo, de mercado e de clientes que atingiram as organizações nas últimas décadas. Abandonou-se o registro de tarefas al tamente padronizadas e previsíveis, passando-se a contemplar genericamente uma ampla possibilidade de responsabilidades com diferentes níveis de complexidade.

Portanto, há que se considerar cada vez mais uma significativa distância entre o conteúdo das descrições de cargos, o que as pessoas real mente realizam no trabalho, e os critérios considerados pel os gestores para remunerar e/ou promover seus empregados. Além disso, Hipólito $(1997,2000)$ destaca que as atividades que constam nas descrições de cargos são, na maioria das vezes, registradas de forma bastante inadequada, deixando de dar resposta à demanda da eqüidade interna.

N esse mesmo sentido, Albuquerque e Oliveira (2002, p. 02) ressal tam que "nos sistemas tradicionais, o tempo é reconhecido, e não a contribuição dos empregados. Assim, o sistema não encoraja o desenvolvimento de habilidades e competências". Ainda nessa linha de argumentação, 0 fato de dar aumento sal arial simplesmente porque a pessoa assumiu uma nova responsabilidade - como acontece no sistema tradicional de remuneração - não é coerente com a prática de recompensar pelo desempenho proposta pel os sistemas de remuneração estratégica (Lawler III, 1986; Hipólito e Silva, 2000).

Barret (1991) destaca que a principal diferença entre as abordagens tradicional e estratégica de remuneração está no fato de que a primeira abordagem remunera a habilidade requerida e prevista na descrição de cargo, enquanto na remuneração estratégica a compensação está voltada para o nível de habilidade da pessoa que desempenha 0 trabalho.

A abordagem estratégica da remuneração está voltada para 0 al inhamento da remuneração à estratégia da empresa, constituindo-se numa fonte de vantagem competitiva de forma que proporcione certo nível de flexibilidade para acompanhar as constantes mudanças, mas que deve também reforçar os objetivos da organização, a longo prazo, pela promoção de uma força de trabalho produtiva e meIhor qualificada (M artocchio, 1998; Wood Jr., 1996).

Portanto, pensar a remuneração de forma estratégica significa que a organização considere o total da remuneração a ser paga, uma vez que a combinação de diferentes al ternativas passa a compor o que real mente é recebido pelo empregado, de um lado, e os custos envolvidos para a empresa, de outro. 0 grande desafio é desenvolver programas de remuneração que suportem e reforcem os objetivos de negócio da organização, o tipo de cultura, clima e comportamentos necessários para a organização ser efetiva (Lawler III, 1990).

Entre as diferentes alternativas para 0 alinhamento estratégico da remuneração, a vinculação ao desempenho, via remuneração variável, tem sido amplamente considerada na literatura sobre o tema como uma das principais formas para assegurar a al avancagem de resultados organizacionais e a conseqüente recompensa para as pessoas (Heery, 1996; Wood J., 1997). Segundo Wood J. (1997), nota-se uma tendência ao aumento da parte variável da remuneração de acordo com o desempenho apurado com base em metas e indicadores previamente estabelecidos. Essa é uma característica da abordagem estratégica da remuneração, que, em certa medida, transfere uma parte do risco da remuneração para o próprio empregado.

\section{Competências: contextualizando sua interface com a gestão de pessoas}

A crescente utilização do termo "competências" e a busca da aplicação dessa noção à administração de Recursos Humanos fazem emergir a necessidade de compreensão das diferentes dimensões que essa lógica abrange. Do ponto de vista teórico, tem-se discutido se a utilização da expressão "competências" retrata ou não um conceito ou se caracteriza uma noção que vem crescendo em aplicabilidade, mas ainda é carente de melhor articulação e clareza de modo a unificar os diferentes discursos que dela tratam.

A grande repercussão na atualidade do conceito de competências se deve, em parte, ao rápido desenvolvimento tecnológico pel o qual passa a sociedade e às mudanças estruturais nas economias ocidentais em direção ao setor de serviços eindústrias baseadas no conhecimento. Esses fatores acarretam às organizações uma maior dependência da competência humana para garantir seu sucesso competitivo (Sandberg, 1993). Assim, as alterações provocadas pel as novas tecnologias no processo de trabal ho têm criado novas exigências para que os trabal hadores respondam de forma adequada a tal realidade.

Pode-se reconhecer uma tendência a considerar as competências humanas como um dos principais fatores que, não passíveis de imitação, asseguram a vantagem competitiva das organizações. De acordo com Brandão e Guimarães (1999, p. 6), "as competências das pessoas que compõem a empresa, aliadas a outros recursos, dão origem e sustentação à competência organizacional".

Em relação às competências individuais, Dutra, 
Hipólito e Silva (1998) identificam duas principais correntes, a americana e a européia, que possuem abordagens diferentes para a noção de competências. N o pensamento europeu pode-se destacar ainda a diferença entre o pensamento britânico e a abordagem francesa.

Entre os teóricos do pensamento americano sobre competências, tem destaque 0 trabalho de Boyatzis (1982), que, influenciado pela visão de McClelland sobre o comportamento como uma função da interação entre a pessoa e o ambiente, define a competência como a capacidade que a pessoa traz para a situação de trabal ho. Enfatiza que a competência individual é necessária mas não suficiente para o desempenho efetivo no trabalho. 0 foco dessa abordagem está voltado para a identificação de características pessoais que assegurem um desempenho superior na situação de trabalho e com maior ênfase para o nível gerencial (Spencer e Spencer, 1993).

De acordo com Steffen (1999), a visão britânica sobre a noção de competências privil egia a identificação de perfis que são a base para programas de formação e certificação de competências. Para Bitencourt e Barbosa (2004), a ênfase está direcionada às tarefas rel ativas aos cargos, sendo a definição de "competências" relacionada aos resultados esperados, traduzidos por indicadores de desempenho exigidos pela estrutura produtiva.

Para além dos atributos pessoais tão destacados no pensamento americano e dos indicadores de desempenho enfatizados pela abordagem britânica, os autores franceses trazem uma contribuição significativa quando resgatam outras dimensões que compõem a competência. Reconhecem que o fato de a pessoa possuir os atributos necessários à função, como também a definição de resultados esperados, não assegura que a competência venha a ser mobilizada de maneira adequada. Zarifian (2001) e Le Boterf (2003) são convergentes em rel ação a esse ponto, e destacam a mobilização da competência como fator determinante dessa nova lógica, reconhecendo a plasticidade que caracteriza tal dinâmica.

Os pensamentos de Le Boterf (2003) e Zarifian (2001) apresentam os seguintes pontos em comum: a interação entre as pessoas como fator integrante da competência; o processo de comunicação como determinante para a construção e o desenvolvimento da competência; a capacidade diante do imprevisto, vista como parte do processo combinatório do esquema cognitivo que permite ações adequadas diante de situações inesperadas; e um lado imponderável da competência que está relacionado à engenhosidade das pessoas.

Os autores nacionais que têm se dedicado à compreensão da noção de competências demonstram claramente que não há uma unicidade sobre o termo, o que interfere diretamente na sua aplicação às práticas de gestão (Albuquerque e Oliveira, 2002; Barbosa, 2003; Bitencourt, 2001; Bitencourt e Barbosa, 2004; Dutra, Hipólito eSilva, 1998; Fleury e Fleury, 2001; Ruas, 2003).

Pode-se identificar um ponto em comum entre os diferentes discursos a respeito das competências. Esse ponto comum diz respeito às transformações nos processos de trabalho, principalmente em função das inovações tecnológicas de produção e da informação, e os fatores de competitividade que demandam novas configurações para as relações que se estabelecem entre as pessoas e seu trabalho.

A aplicação da noção de competências demanda em primeiro lugar que a organização denomine o que é competência e qual 0 al cance de sua aplicabilidade ao modelo de gestão. A partir daí, parte-se para a identificação das competências, que pode ser alcançada por diferentes caminhos, dependendo da abordagem metodológica utilizada. A princípio, não há a indicação de uma forma de identificação de competências mais adequada a ser utilizada pelas organizações, sabendo-se que essa decisão deve ser coerente com o contexto da empresa e com a forma como interagem empresa, empregados e sindicatos (Jenkins e Klarsfeld, 2002).

Rodrigues (2004) analisa diferentes enfoques metodológicos para a identificação de competências e ressalta que há um ponto de convergência referente à ênfase no desempenho em situações concretas como referência para a descrição de competências. Porém, há uma dificuldade intrínseca no processo de descrição das competências relativa ao fator implícito (representação interna) que de fato integra os diferentes saberes e as atitudes necessárias (Levy-Leboyer, 1997). Ou seja, independentemente da metodologia utilizada, haverá sempre um componente "invisível" da competência que diz respeito aos recursos internos mobilizados em uma dada situação que refletem a combinação de diferentes saberes, experiências, traços, características e motivações. Portanto, tal combinação não é apreensível (Le Boterf, 2003; Zarifian, 2001).

Já em relação à recompensa das competências, deve-se considerar a decisão do fator a ser recompensado e a forma de traduzir tal recompensa em práticas de remuneração. N esse contexto, no sistema de pagamento busca-se reconhecer a contribuição das pessoas para o resultado organizacional tendo como princípio a articulação entre as estratégias organizacionais e as práticas de remuneração como forma de sustentar ou promover vantagens competitivas. 


\section{JÚNIA MARÇAL RODRIGUES}

\section{Articular remuneração e competências}

Remunerar as pessoas por suas habilidades e conhecimentos não é algo recente. Conforme destaca Lawler III (1991), empresas de pesquisa e desenvolvimento - ou mesmo outras - têm recompensado grupos de pessoas por suas habilidades e conhecimentos há décadas. Lawler III (1986, 1990), por meio de um breve histórico sobre essa forma de remuneração - skill-based pay -, demonstra que nos Estados Unidos el a foi tipicamente desenvolvida em empresas de manufatura e que sua popularidade tem aumentado significativamente, embora sua aplicação no nível gerencial e de estafe não fosse tão freqüente naquela época.

O utra forma de remuneração também mencionada na literatura sobre o tema é denominada pay-for-knowledge, e, de acordo com Martocchio (1998), é considerada pelos profissionais de remuneração como sinônima de remuneração baseada em competência. Embora existam diferenças entre skill-based pay e pay-for-knowledge, os princípios que direcionam essas formas de remuneração são os mesmos: recompensar as pessoas em função de habilidades e competências.

Com base nessa lógica, torna-se fundamental traduzir a definição de competências em atributos que possam ser mensurados para a verificação do alcance de resultados individuais e, conseqüentemente, organizacionais. Então, a arquitetura do modelo de remuneração dependerá tanto do conceito de competência adotado pela organização como da abordagem metodológica utilizada para sua identificação, considerando a influência mútua desses dois aspectos. Embora a lógica da competência tenha como foco principal a contribuição das pessoas, e também dos grupos, na prática ela ainda se revela vinculada à estrutura de cargos como ponto de partida para sua identificação e posterior desdobramento.

0 fator a ser recompensado, de acordo com a lógica da competência aplicada às práticas de remuneração, tem como inferência que a competência - independentemente de sua definição conceitual - permite 0 alcance dos resultados esperados, sendo a avaliação do desempenho a ferramenta disponível para a verificação de tais resultados. Dessa forma, busca-se, por meio de indicadores, a mensuração dos resultados individuais, entendidos, na lógica da competência, como a conseqüência da sua mobilização ou como as características que diferenciam uma performance superior das demais.

Portanto, esse é um desafio que se apresenta às organizações que pretendem implementar um sistema de remuneração por competências, pois, conforme destaca Fischer A. (1998, p. 160), a "flexibilização da remune- ração somente pode ser implementada em organizações que contarem com processos de aval iação de desempenho estruturados e legitimamente reconhecidos".

Resultados de pesquisas demonstram que, em última instância, o que as empresas têm realmente recompensado é o resultado apresentado e não as competências. E também ressaltam a dificuldade da mensuração dos aspectos intangíveis relacionados às competências. Adicionalmente, parece não haver uma substituição do model o tradicional pela remuneração baseada em competências que traga uma nova conotação referente à maior inserção estratégica nas organizações das práticas de remuneração e/ou da gestão de pessoas.

Nesse sentido, a reflexão sobre a remuneração baseada em competências retoma o papel que a administração de Recursos Humanos tem ocupado nas organizações, uma vez que faz relembrar elementos essenciais da gestão de pessoas e sua vinculação com os resultados organizacionais, função de caráter fundamental para que seus processos agreguem val or aos negócios. Porém, o entendimento da operacionalização da gestão de pessoas depende, em grande parte, de variáveis organizacionais e do modelo de gestão, que influenciam e direcionam as políticas da área de Recursos Humanos. Por isso, a visão de diferentes pessoas envolvidas tanto na concepção quanto operacionalização do modelo de remuneração vinculado às competências é fator decisivo para que o pesquisador possa confrontar diferentes opiniões e, assim, analisar os aspectos complementares e contraditórios da aplicação dessa prática de recompensa.

\section{PROCEDIMENTOS METODOLÓGICOS}

0 problema central desta pesquisa diz respeito à articulação entre as práticas de remuneração e a noção de competências, tendo como objetivo anal isar como essa vinculação tem se traduzido na realidade organizacional, com base nas práticas de remuneração e da interface estabelecida com modelos de gestão de competências. Para isso, foi necessário conhecer a estrutura de remuneração, o modelo de competências e os mecanismos estabel ecidos para viabilizar a remuneração das competências.

Considerando a natureza do problema da pesquisa e de seus objetivos, optou-se pela pesquisa do tipo qualitativo-descritiva como forma de investigação que se propõe abordar "um fenômeno ou situação mediante um estudo realizado em determinado espaço-tempo" (Lakatos, 1999, p. 22). De acordo com Roesch (1999), a pesquisa qual itativa pode ser considerada uma al ternativa metodológica de 
pesquisa em face do predomínio do paradigma positivista, caracterizan do-se pela ênfase nos aspectos subjetivos que permeiam as investigações no campo das ciências sociais. 0 que torna essa forma de pesquisa bastante pertinente em estudos na área de Administração, que notadamente privilegiam a análise de realidades organizacionais como forma de construir e reconstruir um conhecimento de natureza aplicada.

Pelo aspecto da viabilidade da pesquisa, optou-se pelo estudo de um caso visando conhecer em profundidade a dinâmica do modelo de remuneração baseado em competências. Em relação à estratégia do estudo de caso, Laville e Dionne (1999, p. 156) consideram que "se um pesquisador se dedica a um dado caso, é muitas vezes porque ele tem razões para considerá-lo como típico de um conjunto mais amplo do qual se torna o representante".

A escolha do caso para análise teve como base um estudo elaborado por Barbosa (2003) no qual esse autor esquadrinhou as empresas que adotam modelo de competências em Minas Gerais. Do universo de 18 empresas, constatou-se que apenas cinco vinculavam o sistema de remuneração às competências, dentre as quais, três fazem parte de um mesmo grupo. A unidade de análise escolhida para este estudo representa a principal empresa desse grupo.

Por uma questão de sigilo, a organização será denominada neste estudo empresa Beta. A Beta faz parte de um conglomerado de empresas de siderurgia do setor privado, num total de 7 mil funcionários distribuídos entre 12 empresas, instituições e fundações vinculadas ao grupo. Sua composição contempla duas unidades industriais próprias, em duas cidades de M inas Gerais, além de ela ter participação no controle de outras quatro unidades, em função de um processo de reestruturação organizacional e societária, sendo duas no estado de Minas Gerais, uma no interior de São Paulo e outra no estado do Espírito Santo.

Em relação à coleta de dados, optou-se pela entrevista semi-estruturada como principal meio de levantamento das informações. Também foram considerados os documentos fornecidos pela organização com dados rel evantes à compreensão do modelo de remuneração e competências. E como forma complementar foi utilizado o recurso de diário de campo durante a real ização das entrevistas e nas diferentes formas de contato com a organização e seus representantes. 0 diário de campo é um tipo de registro no qual "constam todas as informações que não sejam registro das entrevistas formais, ou seja, observações sobre conversas informais, comportamentos, cerimônias, festas, instituições, gestos, expressões que digam respeito ao tema da pesquisa" (M inayo, 2000, p. 100).

Com base na atribuição das atividades dos profissionais envolvidos com o modelo de remuneração e competências, o grupo de entrevistados totalizou 21 pessoas, entre analistas de recursos humanos, consultores, gerentes de recursos humanos e gestores. As entrevistas com esses profissionais ocorreram nas unidades de Belo Horizonte (A), João Monlevade/Minas Gerais (B), Vitória/Espírito Santo (C) e Piracicaba/São Paulo (D). A Tabela 1 mostra a distribuição dos entrevistados de acordo com o cargo e o total tanto na organização quanto nas unidades pesquisadas.

Para tratamento e análise dos dados, foram identificadas categorias que direcionam a análise qual itativa descritiva considerando a seleção prévia das informações rel evantes à compreensão do fenômeno estudado, a partir de três grandes eixos de análise: a composição do sistema de remuneração, o modelo de competências e a vinculação entre remuneração ecompetências. Tais categorias, no entanto, compreendem subitens que reúnem as informações

Tabela 1 - Grupo de entrevistados

\begin{tabular}{|l|c|c|c|}
\hline \multicolumn{1}{|c|}{ CARGO } & $\begin{array}{c}\text { NÚMERO DE } \\
\text { ENTREVISTADOS }\end{array}$ & $\begin{array}{c}\text { TOTAL NA } \\
\text { ORGANIZAÇÃO }\end{array}$ & $\begin{array}{c}\text { TOTAL NAS UNIDADES } \\
\text { PESQUISADAS }\end{array}$ \\
\hline Analistas de RH & 10 & 14 & 14 \\
\hline Consultora externa (remuneração) & 01 & 01 & 01 \\
\hline Gerente corporativo área de RH & 01 & 05 & 05 \\
\hline Gerente unidade industrial & 01 & 07 & 04 \\
\hline Gerentes de Recursos Humanos das unidades & 04 & 04 & 04 \\
\hline Gestores (unidades) & 04 & 175 & 115 \\
\hline Total & 21 & 206 & 143 \\
\hline
\end{tabular}


necessárias para compreender como a noção de competências se insere no sistema de remuneração, resgatando as razões que levaram à adoção desse modelo, a forma como é estruturado e sua operacionalização.

\section{RESULTADOS}

A compreensão da vinculação entre a noção de competências e a remuneração passa pelo conhecimento da definição de competência utilizada pela organização e pela forma como se relaciona com a estrutura de remuneração. Para tanto, é necessário descrever a composição do sistema de remuneração e do sistema de gestão de desempenho, que é, no caso estudado, a ferramenta que engloba o perfil de competência como um dos el ementos para o cálculo do bônus-meta, que é o fator variável da remuneração vinculado à competência.

0 principal fator que direciona a política de remuneração da Beta é a consideração do valor anual total recebido pelos empregados como um diferencial em relação ao mercado. A empresa busca, mediante a combinação de várias formas de remuneração, manter-se num nível que a torne competitiva na atração e retenção de pessoas no que diz respeito ao quesito remuneração. Os componentes da remuneração total anual são: salário-base, benefícios, remuneração variável, 13으 e 14ํㅗalários.

A política de remuneração definida pela organização para todos os grupos ocupacionais é de que a posição do salário-base corresponda à mediana de mercado. A diferenciação da empresa em relação ao mercado está direcionada para o valor total de remuneração anual, tendo como alvo um posicionamento próximo ao 3ำ quartil, de acordo com as pesquisas salariais. Outro aspecto da política de remuneração que merece destaque é o posicionamento da empresa desfavorável à concessão de aumento real para o salário-base, privilegiando a prática da remuneração variável como forma de equilibrar o ganho total anual recebido por cada empregado.

0 fator variável da remuneração também é diferenciado entre os grupos ocupacionais, da seguinte maneira: (1) participação nos lucros e resultados (PLR), conforme negociações sindicais para o nível operacional e, ainda, grande parte do quadro técnico; e (2) programa de bônus-meta, no qual são elegíveis executivos (inclusive da área comercial), supervisores, profissionais de nível superior, o que inclui administração, operação industrial, vendedores, secretárias e profissionais de nível médio. A remuneração da competência está relacionada a essa segunda alternativa de remuneração variável, atingindo cerca de mil empregados na organização, num total de 3.961, considerando as unidades A, B, C, D e escritórios em Belo Horizonte.

Já na sua origem, o perfil de competências esteve vinculado ao pagamento de uma parcela variável da remuneração. 0 período entreos anos de 1996 e 2000 corresponde à fase de construção do model o de competências vinculado à remuneração, e compreende tanto a definição do perfil de competências para os diferentes grupos ocupacionais como também a el aboração das regras do cálculo utilizado para subsidiar o pagamento da remuneração variável.

A partir do ano de 2000, em função dos resultados obtidos pela avaliação de desempenho e do feedback tanto de avaliadores como de avaliados, foram feitos ajustes no modelo no que diz respeito principalmente ao perfil de competências. Essas alterações decorreram da necessidade de uma atualização constante das competências que realmente contribuam para os resultados organizacionais e que sejam, portanto, específicas do negócio da organização.

A competência é definida pela organização como "o conjunto de comportamentos que levam as pessoas a obterem o resultado esperado da sua performance. Porque o conjunto de comportamento é que determina qual 0 processo que as pessoas usam para atingir resultados (gerente corporativo)". A definição das competências foi inicialmente concebida para dois grupos ocupacionais, a saber: em 1996, para o grupo de executivos; e após um ano, para os profissionais de nível superior. Esse primeiro perfil de competências foi construído pela mesma consultoria que el aborou o plano de cargos e salários, utilizando sua metodologia de entrevistas de evento comportamental, que tem o objetivo de identificar comportamentos típicos de grupos de profissionais considerados de sucesso, ou com resultados acima do esperado, e também de grupos de profissionais com desempenho dentro do esperado. Assim, foi definido um total de 17 competências, distribuídas em função da natureza das atividades de cada grupo ocupacional.

0 desenvolvimento de competências tem como base principal as ações que são acordadas entre o avaliado e seu gestor ao final do processo de avaliação, quando estabelecem o plano de desenvolvimento individual (PDI), que é um plano de ação que indica o que, como e quando fazer, e qual 0 indicador de mensuração para o que será realizado. Entretanto, não há nesse instrumento uma uniformidade a respeito do que se espera e da maneira como deve ser conduzido esse processo de desenvolvimento, no que diz respeito à natureza das ações que indicam o desenvolvimento das competências, bem como 
ao acompanhamento desse plano no intervalo entre uma avaliação e outra.

0 posicionamento das pessoas do nível corporativo (gerente e consultora) é de que o PDI é de responsabilidade de cada funcionário, não havendo formalmente a orientação de uma sistemática de acompanhamento por parte dos gestores. Sendo assim, a definição das ações de desenvolvimento individual se faz em função das competências com pior avaliação, excluindo qual quer tipo de atividade que caracterize treinamento, como, por exemplo, cursos de inglês, MBA e de conhecimento técnico sobre processo produtivo. No entanto, a ação dos gestores demonstra uma diferenciação da postura de acompanhamento dos planos de desenvolvimento individual de seus subordinados, ou até mesmo sobre a concretização de seu próprio PDI.

A remuneração da competência na organização para os cargos de carreira gerencial e carreira técnica ocorre pela remuneração variável mediante pagamento de um bônus anual previamente estipulado, que, à época da coleta de dados, era calculado em função de dois fatores: 0 desempenho da empresa (DE), e o desempenho individual (DI), composto por quatro diferentes dimensões, como será mostrado a seguir.

0 resultado DE também é fator moderador para o cálculo do percentual de bônus-meta a ser pago, sendo 0 cálculo feito pela seguinte fórmula:

Valor-bônus = bônus-meta x (0,5 DE +0,5 DI) x salário-base 100

O bônus-meta é um valor-alvo múltiplo de salários estipulado para cada grade salarial, que contempla até três valores diferentes de salários, de acordo com a estrutura de cargos e salários definida pela metodologia de pontos. 0 desempenho da empresa é medido por resultados, sendo responsáveis o presidente ea diretoria. Aqui seutilizam indicadores financeiros, como market share, ebtida e outros. 0 resultado do cumprimento dessas metas étraduzido num percentual denominado DE. A empresa tem alcançado, em anos consecutivos, um desempenho superior a $100 \%$.

0 percentual de DI é a combinação de quatro fatores diferenciados por peso, tendo a seguinte configuração à época da coleta de dados: $75 \%$ para a responsabilidade por resultados; 15\% para avaliação do perfil de competências; $5 \%$ para a realização do PDI; $5 \%$ para a qualidade da saúde.

Os fatores relativos à realização do PDI e às ações da qualidade da saúde na avaliação de 2005 referem-se ao período de 2004. Tal inclusão foi feita visando minimizar a negl igência tanto no cumprimento das metas de desenvolvimento individual quanto em relação à prevenção da saúde, principalmente a realização dos exames periódicos de saúde.

O perfil de competências é avaliado por meio do sistema de gestão de desempenho, que gera um valor final para o DI, considerando também o resultado do cumprimento das metas mediante a responsabilidade por resultados. A Figura 1 ilustra o processo para a avaliação do perfil de competências. A escala de avaliação varia de 0 a 100\%, sendo considerada a seguinte classificação: 0 - ausente; $25 \%$ - percebida no nível inicial; $50 \%$ - percebida no nível mediano; $75 \%$ - percebida no nível alto; $100 \%$ - percebida no nível pleno.

A área corporativa sinal iza uma ampla facilidade para a operacionalização do processo de avaliação, em função de sua informatização, justificando inclusive a pouca quantidade de pessoas alocadas para esse processo. Todavia, os relatos de gerentes de Recursos Humanos, analistas e gestores usuários do modelo nas diferentes unidades demonstram a necessidade de envolvimento da área de $\mathrm{RH}$ nesse processo.

Em relação às principais facilidades do processo de avaliação das competências, a informatização do sistema é o principal aspecto ressaltado pela maioria dos entrevistados, que ressaltam o fato de o software ser bastante amigável, auto-explicativo e, portanto, de fácil utilização. As dificuldades identificadas no processo de vinculação da remuneração à noção de competências dizem respeito principalmente à disponibilidade de tempo para fazer a avaliação e, até mesmo, à preparação do gestor para exercer seu papel de avaliador.

A reunião de feedback é o ponto mais citado pelos entrevistados de forma ambígua: ao mesmo tempo em que consideram o momento mais importante de todo o processo, é também onde se detectam as maiores falhas na operacional ização. Alguns fatores apontados por dificultarem a prática do feedback são a periodicidade da avaliação, a subjetividade, e a distância do gestor em relação ao subordinado no desempenho das atividades.

Grande parte dos entrevistados também relata as mudanças que ocorreram em função da vinculação de uma parcela variável da remuneração ao perfil de competências. Os principais aspectos percebidos dizem respeito a um maior comprometimento das pessoas pelo conhecimento do que a organização espera de cada empregado e ao direcionamento das ações de treinamento para 0 alcance do perfil de competências. 
Em relação a possíveis modificações no sistema de remuneração e competências, as sugestões concentram-se na preocupação com a atualização das competências e na necessidade de reduzir o intervalo entre as avaliações, como também na inclusão de outros avaliadores, como é característico da avaliação 360․

\section{CONSIDERAÇÕES FINAIS}

Uma breve análise do caso estudado busca confrontar os aspectos teóricos descritos anteriormente com a prática desenvolvida pela organização. Para isso, abordou-se inicialmente o modelo de competências e na seqüência a articulação entre o perfil de competências e o sistema de remuneração, buscando sinalizar as principais dificul- dades da aplicação do conceito de competências, assim como os pontos positivos e reflexões sobre esse tipo de prática, visando seu aperfeiçoamento.

Sobre a definição das competências, deve-se destacar que a metodologia adotada pela empresa utiliza o relato das pessoas como único meio de obter informações. Essa técnica pode deixar lacunas na medida em que o entrevistado pode não se lembrar ou até mesmo não querer falar sobre al guns aspectos do trabal ho (Boyatzis, 1982). U ma metodologia que contemple a observação ou descrição das atividades concretas do trabalho poderia ampliar as informações que levam à definição de competências. Tal forma de identificação permitiria ainda mel hor visualização de que as diferentes dimensões das competências são interdependentes e, por isso, sua identificação pode ficar limitada quando feita de forma dissociada.

Figura 1 - Processo para a realização da gestão do desempenho

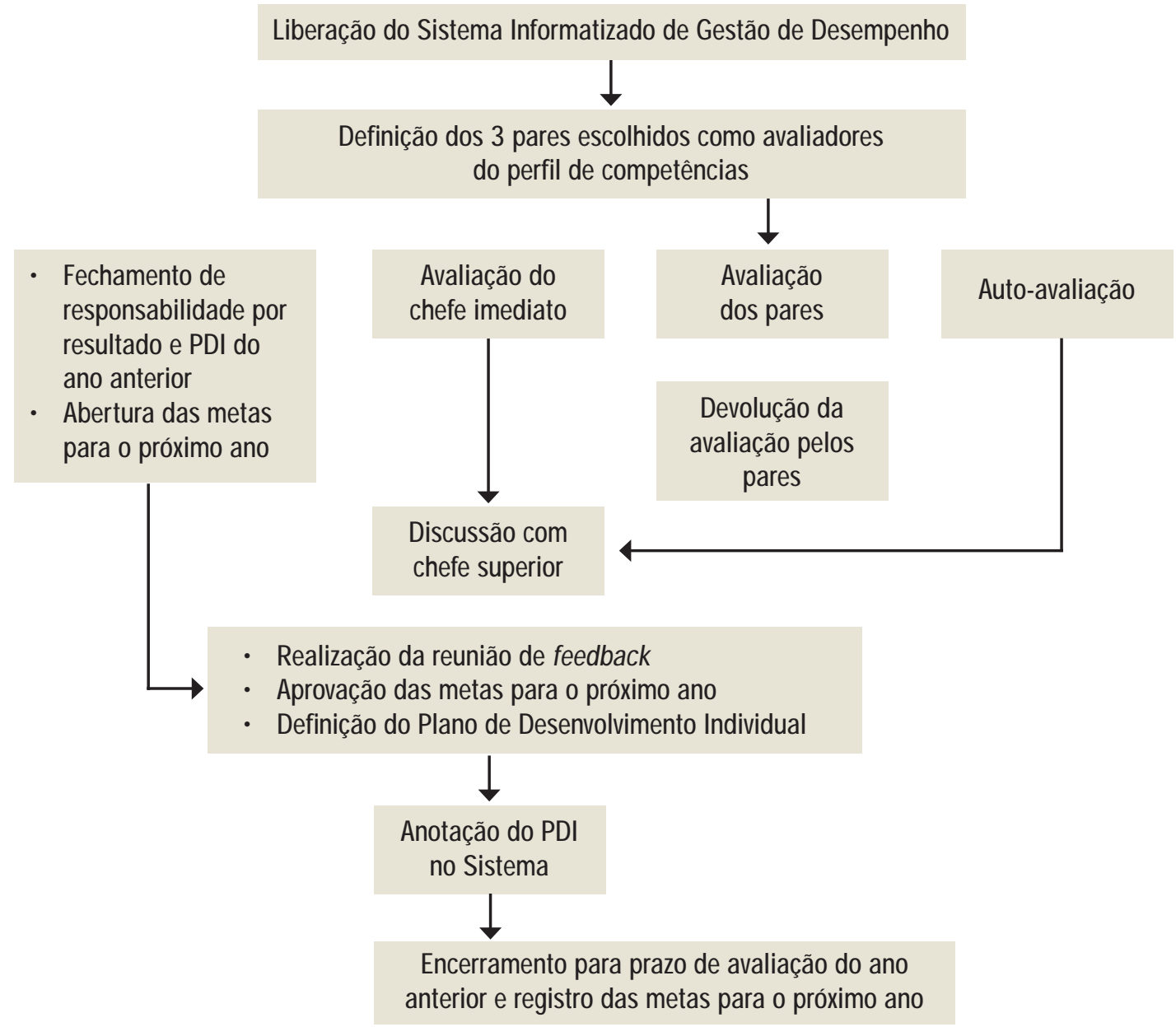

Fonte: Adaptado pela autora a partir de documentos fornecidos pela empresa. 
Além disso, o caso estudado também evidenciou uma lacuna na medida em que não são definidas competências organizacionais e pouca ou nenhuma preocupação com o futuro é considerada na definição do perfil de competências. Essa lacuna de não identificar competências organizacionais para posterior desdobramento em competências individuais restringe a perspectiva estratégica do modelo de competências e sua contribuição para a competitividade, pois as declarações organizacionais sobre estratégias e vantagens competitivas estão relacionadas basicamente à natureza do negócio e aos recursos físicos para sua consecução.

Ainda se deve registrar que os diferentes perfis de competência adotados para os sete grupos ocupacionais revel am certo grau de homogenei dade, pois têm como evidências de uma competência comportamentos idênticos entre grupos funcionais que real izam tarefas de natureza diferenciada. Pergunta-se: não teria essa padronização das competências o mesmo caráter prescritivo tão criticado nas tradicionais descrições de cargo que a lógica de competências pretende, a princípio, extrapolar?

0 desenvolvimento das competências, aspecto preponderante para sua remuneração, revela uma forte transferência da responsabilidade pelo desenvolvimento da competência para o empregado, desvinculada de uma sistemática organizacional para que isso aconteça. Dado que a organização assume que toda e qualquer atividade de treinamento não pode ser caracterizada como PDI, sendo o desenvolvimento individual de responsabilidade do empregado, muito pouco resta a ele fazer nesse sentido. Diferentemente, gera uma expectativa de superação das dificuldades individuais, qual quer que seja sua natureza, que se mostra presente na execução das atividades de trabal ho. M esmo que para isso sejam demandadas ações que extrapolem, e de muito, o espaço organizacional.

No caso estudado, a remuneração da competência depende da combinação de vários fatores para que seja definida, pois a competência compõe o cálculo do fator variável da remuneração, que é fruto também do $D E$, do cumprimento de metas por meio da responsabilidade por resultados, da realização do plano de desenvolvimento individual e da qualidade da saúde.

Prerrogativas que delimitam conceitual mente um sistema de remuneração e competências, pela via de recompensar os resultados individuais que estão relacionados aos organizacionais, consideram que haja uma combinação de metas e indicadores em três níveis: individual, de grupos e organizacionais. Dessa maneira, torna-se mais eqüitativo o esforço para o alcance dos resultados (Barbosa, 2003; Hipólito, 2000; Lawler III, 1990). 0 mo- del o estudado contempla duas dessas dimensões quando considera o desempenho da empresa e as metas individuais de cada empregado frente às diretrizes desdobradas desde a presidência. Além disso, o peso de $75 \%$ para 0 fator responsabilidade de resultados demonstra a ênfase muito mais nos resultados pela mensuração quantitativa das metas do que no perfil de competências, considerado como requisito para 0 al cance dos resultados.

Embora se destaque a competência de trabalho em equipe (considerada em seis dos sete grupos contemplados pelo modelo), a dinâmica do modelo não contempla a prática dessa competência por meio do estabelecimento, por exemplo, de metas coletivas. Essa situação pode levar a um excesso da individualização, dificultando os níveis de cooperação entre as pessoas, fator-chave para a mobilização das competências (Wood Jr., 1997; Zarifian, 2001), além do enfraquecimento de eventuais reivindicações coletivas que possam ter maior expressividade do que questões tratadas individualmente (H eery, 1996). Há de se considerar também o risco de que se fomente uma competição interna pela busca do resultado individual, mais que dos resultados que favoreçam a organização.

Remunerar com base no desempenho, considerando que o resultado da avaliação de desempenho é fruto da competência em ação, reduz a competência a um resultado padronizado que não demonstra efetivamente sua parcela de contribuição. N esse sentido, vale retomar a consideração de Le Boterf (2003) sobre o aspecto imponderável da competência, associado à peculiaridade de cada ação, que não acontece de maneira idêntica em momentos diferenciados. Essa dimensão não é passível de apreensão, sendo limitadas as tentativas de traduzi-la em um valor a ser pago, como forma de recompensa. Isso porque seu dinamismo e unicidade denunciam que nenhuma definição ou padronização prévia de um perfil de competências contempla tais aspectos, vitais no processo de mobilização das competências.

De maneira geral, o programa de bônus-meta está, em certa medida, mais atrel ado à estratégia definida pela organização, em que o total pago anual mente aos empregados deve aproximar-se do 30 quartil, confirmando pesquisas salariais. Portanto, a remuneração da competência é feita indiretamente, combinando fatores relacionados aos resultados da empresa e das pessoas.

0 caso pesquisado sinal iza a oscilação entre a retórica e a realidade da remuneração baseada em competências. 0 modelo revela que nenhuma abordagem conceitual sobre a noção de competências é, isolada ou exclusivamente, suficiente para dar suporte ao desdobramento da competência como fator a ser remunerado, uma vez que 
a multiplicidade conceitual da noção de competências permite diferentes leituras da realidade, de acordo com o enfoque considerado. A partir de um perfil de competências, independentemente da abordagem metodológica utilizada para sua definição, é feita uma inferência mediante a avaliação de desempenho de que a presença das competências (ou a competência em ação), previamente definidas, conduz ao desempenho, que é então avaliado e, por conseqüência, remunerado.

Deve-se considerar também que as características do modelo e as diferenças de relatos entre os responsáveis pela sua concepção e aquel es que fazem sua operacionalização (analistas de recursos humanos e gestores) reforçam a dinâmica entre a retórica do modelo e sua prática, como, por exemplo: i) transparência do sistema; ii) falta de consenso quanto às ações de desenvolvimento das competências; iii) o peso relativo das metas para o cálculo da remuneração variável é significativamente superior ao perfil de competências; iv) o perfil de competências está vinculado, principalmente, à estrutura tradicional de cargos, sem nenhuma referência às competências organizacionais como direcionadoras das competências individuais; v) a prática do feedback mostra-se bastante deficiente; vi) o componente variável da remuneração acaba sendo um anteparo à política tradicional centrada na remuneração fixa; vii) a organização repassa ao empregado a responsabilidade do desenvolvimento das competências definidas para sua função; vii) as metas são definidas em caráter individual, embora tenha destaque a competência de trabalho em equipe.

Essa retórica pode ser minimizada se for levada à prática. Para tanto, é necessário um sólido processo de identificação, desenvolvimento e reconhecimento das competências individuais, em linha com as competências organizacionais, o que não aconteceu no caso estudado. Finalmente se devem preparar gestores para a efetiva gestão de pessoas baseada em competências. Esses gestores deverão participar e envolver-se no processo de concepção do modelo atuando como elos entre as estratégias e demandas organizacionais e a realidade operacional das diferentes áreas/unidades de uma organização. Dessa forma, articular-se-ão melhor os resultados organizacionais e das áreas individuais e o perfil de competências minimizará a discrepância do peso relativo atribuído a cada uma dessas dimensões. Para tanto, a atuação da área de Recursos Humanos torna-se preponderantenesse processo de formação de gestores.

0 modelo de remuneração estudado neste trabal ho impede que se façam general izações, pois se trata da análise deum caso único, com todas as suas particularidades (Yin,
2001). Ao mesmo tempo, é importante destacar que uma realidade específica permitiu a reflexão sobre aspectos teóricos e práticos fundamentais na discussão que tem sido feita sobre os modelos de remuneração, principalmente aqueles baseados em competências.

\section{REFERÊNCIAS}

ALBUQUERQUE, L. G.; OLIVEIRA, P. M. Implementação do modelo de gestão de pessoas por competências: o caso da Oxiteno. In: EN CONTRO NACIONAL DA ASSOCIAÇÃO NACIONAL DOSPROGRAMASDE PÓSGRADUAÇÃO E PESQUISA EM ADMINISTRAÇÃO, 26., 2002, Salvador. Anais. Salvador: ANPAD, 2002.

BARBOSA, A. C. Q. É possível remunerar pelas competências? Discurso e prática frentea frente- um estudo em grandes organizações. In: EN CONTRO NACIONAL DA ASSO CIAÇÃO NACIONAL DOSPROGRAMASDE PÓSGRADUAÇÃO E PESQUISA EM ADMINISTRAÇÃO, 27., 2003, Atibaia. Anais. Atibaia: AN PAD, 2003.

BARBOSA, A. C. Q . G estão de competências em organizações: um mosaico da teoria prática. In: BARBOSA, A. C. Q. (O rg.). I Workshop gestão de competências em organizações. Belo Horizonte: UFMG/IKS, 2001.

BARRET, G. V. Comparison of skill-based pay with traditional job evaluation techniques. Human Resources Management Review, v. 1, n. 2, p. 97-105, 1991.

BITEN COURT, C.; BARBOSA, A. C. Q. A gestão de competências. In: BITEN COURT, C. (O rg.). G estão contemporânea de pessoas: novas práticas, conceitos tradicionais. Porto Alegre: Bookman, 2004.

BITTEN COURT, C. C. A gestão de competências gerenciais: a contribuição dos princípios da aprendizagem organizacional. Projeto de Tese - PPGA/ UFRGS, Porto Alegre: 2001.

BOYATZIS, R. E. The Competent Manager: A Model for Effective Performance. New York: Willey, 1982.

BRANDÃO, H. P.; GUIMARÃES, T. A. Gestão de competências e gestão de desempenho: tecnologias distintas ou instrumentos de um mesmo constructo. In: ENCONTRO NACIONAL DA ASSOCIAÇÃO NACIONAL DOS PROGRAMAS DE PÓS-GRADUAÇÃO E PESQUISA EM ADMINISTRAÇÃO, 23., 1999, Foz do Iguaçu. Anais. Foz do Iguaçu: ANPAD, 1999.

BRISO LLA Jr., C. B. A remuneração variável mudando paradigmas na administração salarial: um estudo no setor bancário. Dissertação (M estrado em Administração) - USP, São Paulo, 1994.

DUTRA, J. S.; HIPÓLITO, J. A. M.; SILVA, C. M. Gestão por competência: o caso de uma empresa do setor de telecomunicações. In: EN CONTRO NACIONAL DA ASSOCIAÇÃO NACIONAL DOSPROGRAMASDE PÓSGRADUAÇÃO E PESQUISA EM ADMINISTRAÇÃO, 22., 1998, Foz do Iguaçu. Anais. Foz do Iguaçu: ANPAD, 1998.

FISCHER, A. L. A. Constituição do Modelo Competitivo de Gestão de Pessoas no Brasil - um estudo sobre empresas consideradas exemplares. Tese (Doutorado em Administração) - FEA/USP, São Paulo 1998. 


\title{
ARTIGOS •REMUNERAÇÃO E COM PETÊNCIAS: RETÓRICA OU REALIDADE?
}

FLEURY, A.; FLEURY, M. T. L. Estratégias empresariais e for mação de competências: um quebra cabeça caleidoscópio. São Paulo: Atlas, 2001.

HEERY, E. Risk, representation and new pay. University Press: Personel Review, v. 25, n. 6, p. 54-65, 1996.

HIPÓLITO, J. A. M. Mudando paradigmas na administração de salários. In: ENCONTRO NACIONAL DA ASSOCIAÇÃO NACIONAL DOS PROGRAMASDE PÓS-GRADUAÇÃO E PESQUISA EM ADMINISTRAÇÃO, 21., 1997, Rio de Janeiro. Anais. Rio de Janeiro: AN PAD, 1997.

HIPÓ LITO, J. A. M. Competências e níveis de complexidade do trabalho como parâmetros orientadores de estruturas salariais. In: ENCONTRO NACIONAL DA ASSOCIAÇÃO NACIONAL DOS PROGRAMAS DE PÓS-GRADUAÇÃO E PESQUISA EM ADMINISTRAÇÃO, 24., 2000, Florianópolis. Anais. Florianópolis: AN PAD, 2000.

HIPÓLITO, J. A. M.; SILVA, C. M. Metodologia de pesquisa salarial por competências: aplicação e resultados. In: ENCONTRO NACIONAL DA ASSO CIAÇÃO NACIONAL DOS PROGRAMAS DE PÓS-GRADUAÇÃO E PESQUISA EM ADMINISTRAÇÃO, 24., 2000, Florianópolis. Anais. Florianópolis: AN PAD, 2000.

JENKINS, A.; KLARSFELD, A. Understanding 'individualization' in human resource management: the case of skill-based pay in France. International Journal of Human Resource M anagement, v. 13, n. 1, p. 198-211, 2002.

LAKATOS, E. M. Fundamentos de metodologia científica. São Paulo: Atlas, 1999.

LAVILLE, C.; DIONNE, J. A construção do saber: manual de metodologia da pesquisa em ciências humanas. Belo Horizonte: Editora UFMG, 1999.

LAW LER III, E. E. What is wrong with point factor job evaluation. Management Review, v. 75, n. 11, p. 44-49, 1986.

LAW LER III, E. E. Strategic Pay: Aligning Organizational Strategies and Pay Systems. California: Jossey-Bass, Inc., 1990.

LAW LER III, E. E. Paying the person: a better approach to management. Human Resource Management Review, v. 1, n. 2, p. 145-154, 1991.

LE BOTERF, G. D esenvolvendo a competência dos profissionais. Porto Alegre: Artmed, 2003.

LEVY-LEBOYER, C. Gestión de las competencias. Barcelona: Ediciones Gestión, 1997.
MARTOCCHIO, J. J. Strategic Compensation: A Human Resource Management Approach. New Jersey: Prentice Hall, 1998.

MINAYO, M. C. S. 0 desafio do conhecimento: pesquisa qualitativa em saúde. São Paulo: Hucitec-Abrasco, 2000.

RIBEIRO, L. M. M.; GUIMARÃES, T. A.; SOUZA, E. C. L. Remuneração baseada nas competências: o ponto de vista de gestores de uma empresa financeira estatal. In: ENCONTRO NACIONAL DA ASSOCIAÇÃO NACIONAL DOS PROGRAMAS DE PÓS-GRADUAÇÃO E PESQUISA EM ADMINISTRAÇÃO, 25., 2001, Campinas. Anais. Campinas: AN PAD, 2001.

RODRIGUES, M . A. Gestão das competências em organizações: diferencial produtivo ou retórica gerencial? Um estudo de caso em empresa de manufatura contratada. Dissertação (M estrado em Engenharia da Produção), DEP/UFMG, Belo Horizonte, 2004.

ROESCH, S. M. A. Projetos de estágio e de pesquisa em administração. São Paulo: Atlas, 1999.

RUAS, R. G estão por competências: uma contribuição à perspectiva estratégica da gestão de pessoas. In: EN CONTRO NACIONAL DA ASSOCIAÇ̃̃O NACIONAL DOSPROGRAMASDE PÓS-GRADUAÇÃO E PESQUISA EM ADMINISTRAÇÃO, 27., 2003, Atibaia. Anais. Atibaia: AN PAD, 2003.

SANDBERG, J. Human competence at work: a managerial problem. In: SANDBERG, J. Human Competence at Work. Boston: John Wiley, 1993.

SPEN CER. L. M.; SPEN CER, S. M. Competenceat Work: Models for Superior Performance. England: John Wiley, 1993.

STEFFEN, I. Tendências no mercado de trabalho e políticas de educação profissional. Turim, OIT, 1999 (traduzido).

W OOD Jr, T. Remuneração estratégica: a nova vantagem competitiva. São Paulo: Atlas, 1996

WOOD Jr, T. Remuneração por habilidades e competências. São Paulo: Atlas, 1997.

YIN , R. K. Estudo de caso: planejamento e métodos. Porto Alegre: Bookman, 2001

ZARIFIAN, P. Objetivo competência: por uma nova lógica. São Paulo: Atlas, 2001.

\section{Artigo recebido em 22.11.2005. A provado em 18.07.2006.}

\author{
Júnia Marçal Rodrigues \\ Pesquisadora associada do Núcleo Interdisciplinar sobre Gestão em Organizações ( Não) \\ Empresariais (Nig.one/UFM G) e do Observatório de Recursos Humanos em Saúde - UFM G. \\ Professora substituta da FACE/UFMG. Professora do Instituto J. Andrade. Mestre em \\ Administração pelo Cepead-UFMG. \\ Interesses de pesquisa nas áreas de gestão de competências, remuneração, administração \\ de recursos humanos e gestão da informação. \\ E-mail: juniamarcal @terra.com.br \\ Endereço: Rua Matipó, 262, apto. 201, Bairro Santo Antônio, Belo Horizonte - MG, \\ 30350-210.
}

